\title{
Manual de Enfermagem de um hospital modelo-referência da cidade de São Paulo nos anos 1970
}

\author{
The Nursing Manual of a reference-model hospital in the city of São Paulo in the 1970's
}

Manual de Enfermería de un hospital modelo-referencia de la ciudad de São Paulo, en los años 70

\section{Danilo Fernandes Brasileiro¹, Maria Cristina Sanna²}

\footnotetext{
Enfermeiro. São Paulo, SP, Brasil. E-mail: daniloenfermagem@hotmail.com.

${ }^{2}$ Enfermeira, Doutora em Enfermagem. Professora do Programa de Pós-Graduação em Enfermagem da Escola de Enfermagem da Universidade Federal de São Paulo. São Paulo, SP, Brasil. E-mail: mcsanna@uol.com.br.
}

\section{RESUMO}

Estudo descritivo, histórico-documental que objetivou descrever o conteúdo sobre o gerenciamento de recursos para a assistência de enfermagem de que tratava o Manual da Subdivisão de Enfermagem do Hospital das Clínicas da Faculdade de Medicina da Universidade de São Paulo. A fonte do estudo foi a segunda edição do Manual da Subdivisão de Enfermagem, datado de 1973. A análise empregou o referencial teórico - "Estrutura do Conhecimento de Administração em Enfermagem", que permitiu classificar e apresentar os achados em oito categorias. As categorias denominadas Prática de Administração de Recursos Financeiros e Prática de Administração de Recursos Físicos foram as menos expressivas. Concluiu-se que a formulação da estrutura administrativa do trabalho de enfermagem expressa no manual, além de pioneira e sistematizada, abrangia espectro relevante de práticas de gerenciamento do serviço de enfermagem. Descritores: História da Enfermagem; Administração de Serviços de Saúde; Administração Hospitalar.

\section{ABSTRACT}

The objective of this descriptive, historical-documental study was to describe the content regarding the management of resources for nursing care addressed in the Nursing Subdivision Manual of the University Hospital of the University of São Paulo Faculty of Medicine. The source for the study was the second edition of the Nursing Subdivision Manual, of 1973. The analysis was performed using the theoretical framework - "Nursing Management Knowledge Structure", which permitted to classify and present the findings as eight categories. The least expressive categories were Financial Resources Management Practice and Physical Resources Management Practice. In conclusion, the formulation of the administrative structure of nursing practice expressed in the manual, in addition to being pioneer and systematized, addressed an important spectrum of managerial nursing practices.

Descriptors: History of Nursing; Health Services Administration; Hospital Administration.

\section{RESUMEN}

Estudio descriptivo, histórico-documental, que objetivó describir los contenidos sobre gerenciamiento de recursos para la atención de enfermería tratados en el Manual de la Subdivisión de Enfermería del Hospital de Clínicas de la Facultad de Medicina de la Universidad de São Paulo. La fuente de estudio fue la segunda edición del Manual de la Subdivisión de Enfermería, con fecha 1973. El análisis empleó el referencial teórico “Estructura del Conocimiento de Administración en Enfermería", que permitió clasificar y presentar los hallazgos en ocho categorías. Las categorías denominadas Práctica de Administración de Recursos Financieros y Práctica de Administración de Recursos Físicos fueron las menos expresivas. Se concluyó en que la formulación de la estructura administrativa del trabajo de enfermería expresada en el manual, además de pionera y sistematizada, abarcaba un relevante espectro de prácticas de gerenciamiento del servicio de enfermería.

Descriptores: Historia de la Enfermería; Administración de los Servicios de Salud; Administración Hospitalaria. 


\section{INTRODUÇÃO}

A Faculdade de Medicina e Cirurgia de São Paulo (FMCSP) foi criada pela Lei n 1357 de 19 de dezembro de 1912 e regulamentada pelo Decreto $n^{\circ} 2.344$ de 21 de janeiro de 1913. Inicialmente, por não possuir sede própria, suas clínicas funcionavam em locais provisórios, como as dependências da Santa Casa de Misericórdia de São Paulo. No ano de 1915, uma comissão de estudiosos da Fundação Rockefeller, em visita ao Brasil, no intuito de avaliar potenciais instituições a serem apoiadas por ela, cogitou, dentre muitas, investir na FCMSP, apoio que se firmou no ano seguinte. Para tanto, foi firmado um acordo com o Governo do Estado de São Paulo, em que a Fundação Rockfeller doaria recursos para construção de sede própria para FMCSP e aquela, por sua vez, deveria mobilizar esforços para a construção de um hospital a ela vinculado(1-2).

Em 25 de janeiro de 1920, iniciaram-se as obras de construção da sede e, em 15 de março de 1931, o edifício da FCMSP foi inaugurado, com transferência imediata das cadeiras de disciplinas básicas para o mesmo; porém as clínicas continuavam a funcionar na Santa Casa de Misericórdia de São Paulo por falta de um hospital

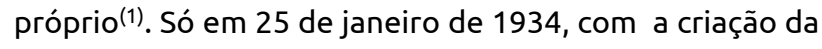
Universidade de São Paulo (USP), a FMCSP foi a ela incorporada e, mais tarde, em 10 de outubro de 1938, durante o governo de Adhemar de Barros, iniciou-se a construção do Hospital das Clínicas da Faculdade de Medicina da Universidade de São Paulo (HCFMUSP), inaugurado em 19 de abril de 1944. A partir dessa data, paulatinamente as enfermarias das clínicas foram se transferindo da Santa Casa de Misericórdia para o HCFMUSP, o que foi concluído no ano de $1948^{(1)}$.

O primeiro quadro de funcionários permanentes foi regulamentado pelo Decreto Lei nº 13.389 de $1^{\circ}$ de junho de 1943, formado por um superintendente, um assistente, um contador-chefe, um médico anestesistachefe, um dentista-chefe, um tesoureiro, um médicochefe, um chefe de arquivo médico, um almoxarife e servidores extranumerários (2). Não demorou muito para que aumentasse a demanda de trabalho para atender à complexidade da estrutura envolvida e atividades nela a serem executadas, dando espaço para que outras classes profissionais se firmassem, como nutricionistas, farmacêuticos, assistentes sociais e, sem dúvida, as diferentes categorias de trabalhadores de enfermagem ${ }^{(1)}$.
A estrutura inicial do Serviço de Enfermagem foi planejada e organizada pouco antes da inauguração do HCFMUSP, em agosto 1942, pela sua primeira diretora nomeada- Hilda Anna Krisch, que permaneceu na função até outubro de 1944. Em maio de 1945, foi nomeada para a direção da Subdivisão de Enfermagem do HCFMUSP, Clarice Della Torre Ferrarini, que permaneceu no cargo por 24 anos, assumindo, por sua vez, o legado deixado por Hilda Anna Krisch, com aproximadamente 300 funcionários, em sua maioria atendentes de enfermagem, seguidos de auxiliares de enfermagem, enfermeiros práticos licenciados e enfermeiros. Apesar das adversas condições de trabalho, Clarice Ferrarini contribuiu ativamente рага o desenvolvimento da Enfermagem nessa instituição, durante o tempo em que lá atuou e, dentre seus feitos, destacam-se a participação na implantação da Unidade de Terapia Intensiva no Pronto Socorro, do Centro de Recuperação Pós-Anestésica, da Unidade de Desenvolvimento e Treinamento de Pessoal, e a criação da Primeira Comissão de Infecção Hospitalar, além de coordenar a elaboração do "Manual de Educação em Serviço" e do "Manual da Subdivisão de Enfermagem"(3-4).

O "Manual da Subdivisão de Enfermagem" teve sua primeira edição publicada em 1967, com 132 páginas, assinado por Romilda Cerqueira do Amaral Filha, Clarice Della Torre Ferrarini e Antonieta Chiarello. Sua elaboração contou com a colaboração de 13 enfermeiros que desempenhavam a função de supervisores de enfermagem e determinava, em seu conteúdo, a padronização das atividades administrativas que envolviam todos os membros da equipe ${ }^{(5)}$.

Manual de Organização de Serviço de Enfermagem é um instrumento que expressa sistematicamente normas, rotinas, missão institucional, característica da clientela a ser assistida, disponibilidade e organização de recursos humanos e materiais, entre outros. Além de sua função operacional, esse instrumento fornece respaldo legal ao exercício profissional dos membros da equipe de trabalho a que este se refere ${ }^{(6)}$. Estruturalmente, os manuais sofreram (e ainda sofrem) grande influencia da Teoria Cientifica (de Taylor) e Teoria Clássica da Administração (de Fayol), por serem baseados em preceitos norteadores como divisão de funções, hierarquização do trabalho e padronização de tarefas. Na Enfermagem brasileira, o primeiro registro desse tipo de ferramenta é do ano de 1934, elaborada com franca influencia da literatura norte- 
americana, porém consistia em um manual com enfoque na área assistencial. Só a partir das décadas de 1950 e 1960, iniciou-se a incorporação desse instrumento para subsidiar ações na área gerencial; ainda assim, em sua maior parte, fruto de traduções da língua inglesa, identificando-se exíguas e isoladas iniciativas brasileiras com essa abordagem ${ }^{(7)}$.

A publicação em análise está entre esses poucos exemplos de instrumentos dessa natureza existentes no país, à época. Vale ressaltar que sua elaboração e publicação se deu entre dois momentos estratégicos para o ensino de administração em enfermagem: as modificações dos currículos mínimos para o ensino em enfermagem, expressos no Рагесег 271/62 e no Parecer 163/72 do Conselho Federal de Educação, que deram algum destaque a esse conteúdo, em suas formulações.

A finalidade do manual citado, além de regimentar, se voltava ao planejamento, execução e avaliação da organização do serviço de enfermagem no final da década de 1960, num dos primeiros hospitais universitários do país, período caracterizado por medicalização da saúde, expansão da assistência médica curativa, especialização e elevação da complexidade de estabelecimentos hospitalares. Frente a isso, questiona-se: Qual o espectro de abrangência do gerenciamento de recursos para assistência de enfermagem tratados no "Manual da Subdivisão de Enfermagem" do HCFMUSP?

Em resumo, justifica-se a relevância de realização do presente estudo por sua contribuição para o resgate de uma pequena página da história de um serviço de enfermagem pioneiro de um hospital de modeloreferência em nível nacional e internacional, e pela importância atribuída a esses manuais no passado, tanto é que fora citado hipoteticamente como possível tema de trabalho de Tese de Livre-Docência da diretora da Divisão de Enfermagem do HC-FMUSP no ano $1973^{(2)}$. Além disso, os manuais administrativos tiveram sua importância revitalizada no presente pois, em tempos de acreditação hospitalar, são considerados instrumentos estratégicos de comunicação organizacional que viabilizam, sistematizam e legitimam as informações, favorecendo a interação da equipe de enfermagem entre si e com as demais áreas técnicas e de apoio que funcionam em estabelecimentos hospitalares, resguardando sua autonomia e estabelecendo padrões de corresponsabilidade ${ }^{(8)}$.
Nessa perspectiva, o objetivo do estudo foi descrever o espectro de abrangência do gerenciamento dos recursos para a assistência de enfermagem tratados no “Manual da Subdivisão de Enfermagem” do HCFMUSP.

\section{MÉTODO}

Estudo descritivo, histórico-documental, definido como aquele que, por meio de coleta sistemática e avaliação minuciosa de dados relativos à ocorrências passadas, tem o intuito de responder perguntas referentes às causas ou tendências dos eventos passados que podem lançar luz sobre os comportamentos ou práticas atuais ${ }^{(9)}$. A pesquisa documental é compreendida como aquela que se baseia em documentos enquanto fontes para estudos, sejam estes jornais, fotografias, filmes, gravações ou documentos legais, dentre outros, que constituem matéria-prima a partir da qual o pesquisador irá desenvolver sua investigação e análise ${ }^{(9)}$.

A fonte direta do estudo foi o "Manual da Subdivisão de Enfermagem do HCFMUSP", que teve sua primeira edição publicada em 1967, mas não mais está disponível para consulta, mesmo após buscas em arquivos do Centro de Educação Continuada da instituição em foco, em arquivos pessoais de ex-funcionários e de bibliotecas especializadas no campo da enfermagem.

O exemplar analisado corresponde a sua segunda e ultima edição e foi obtido, por empréstimo, na primeira quinzena de janeiro de 2012, do acervo do Centro de Educação Permanente de Enfermagem do HCFMUSP. Essa edição foi publicada em 1973 e é composta de três capítulos e 132 páginas, de autoria de Romilda Cerqueira do Amaral Filha, Edoília Maria Teixeira e Maria Camargo de Oliveira Falcão, além de contar com a participação de 17 supervisores de enfermagem como colaboradores ${ }^{(5)}$. A primeira e terceira autoras foram diretoras da Divisão de Enfermagem e a segunda trabalhou na instituição por mais de 40 anos. A terceira foi também a primeira presidenta do Conselho Regional de Enfermagem Seção São Paulo.

Utilizou-se, ainda, fontes indiretas рага contextualização histórica e fundamentação teórica, que se constituíram em publicações sobre o tema, obtidas após buscas realizadas no site da BVS - Enfermagem, nas bases de dados SciELO e BDENF, e consulta ao acervo da Biblioteca da Escola de Enfermagem da Universidade de São Paulo. 
Em seguida, iniciou-se a análise do conteúdo à luz do referencial teórico proposto por Sanna ${ }^{(10)}$, que definiu a "Estrutura do Conhecimento de Administração em Enfermagem" através de uma proposta taxonômica composta por oito categorias, com respectivas subcategorias, a saber:

I-Bases Ideológicas e Teóricas com cinco subcategorias (Teorias da Administração, Filosofia do Serviço de Enfermagem, Políticas de Saúde, Legislação sobre Saúde, Ensino e Trabalho, Mercado de Trabalho e Área de Atuação)

II- Métodos de Intervenção, com quatro subcategorias (Planejamento, Tomada de Decisão, Supervisão e Auditoria)

III- Prática de Administração de Recursos Humanos, com seis subcategorias (Dimensionamento, Recrutamento, Seleção, Distribuição, Avaliação de Desempenho e Educação Permanente)

IV- Prática de Administração de Recursos Materiais, com seis subcategorias (Previsão, Aquisição, Armazenamento, Conservação, Distribuição e Controle)

V- Prática de Administração de Recursos Físicos, com seis subcategorias (Arquitetura, Projeto, Decoração, Legislação e Denominação de Compartimentos, Segurança do Cliente/Profissionais e Riscos Ocupacionais)

VI- Prática de Administração de Recursos Financeiros, com quatro subcategorias (Financiamento, Orçamento, Custos e Produtividade)

VII- Prática de Administração de Recursos Políticos, com sete subcategorias (Estrutura Organizacional, Poder e Cultura, Conflito e Negociação, Liderança, Motivação, Mudança e Relações Interdepartamentais)

VIII- Prática de Administração de Recursos de Informação, com cinco subcategorias (Comunicação, Prontuário do Cliente, Manuais Organizacionais, Documentos Administrativos, Impressos e Formulários Eletrônicos)

Executou-se a análise mediante o cotejamento entre o conteúdo da obra e o referencial teórico supracitado, por meio da classificação do conteúdo (recursos gerenciais de enfermagem) conforme as categorias/subcategorias atinentes. Por fim, os achados foram descritos e discutidos com base na literatura científica apropriada.
Por tratar-se de estudo com registro de dados disponíveis, não foi necessária a submissão do projeto para análise por Comitê de Ética em Pesquisa com seres humanos, conforme determina a legislação vigente que regula esta pauta(11).

\section{RESULTADOS E DISCUSSÃO}

\section{Bases ideológicas e teóricas}

Não se encontrou referência explícita em nenhum momento para a subcategoria denominada Teorias da Administração, embora esta estivesse subjacente à própria iniciativa de sua elaboração, o que é explicado pelas principais influencias ideológicas nesse período, em que a Enfermagem tinha as Teorias Clássica e Científica incorporadas ao seu fazer administrativo, desde a estruturação do currículo prescrito para a formação de enfermeiros, até a sustentação de sua "práxis"(12).

A Filosofia do Serviço de Enfermagem foi abordada em vários momentos, dentre eles, no primeiro artigo do manual, que diz:

"Art. $1^{\circ}$ A Subdivisão de Enfermagem, que faz parte da Divisão de Serviços Técnicos, é diretamente subordinada ao Sr. Superintendente e tem por finalidade: I- Planejar $e$ executar todas as atividades específicas e auxiliares de enfermagem do hospital; II- Cooperar no atendimento dos pacientes e executar as prescrições médicas; III- colaborar nas pesquisas médicas." Cap. I- pag. - 19

A subcategoria Políticas de Saúde, conforme o exemplo descrito a seguir, tinha seu papel na organização do Serviço de Enfermagem abordada do seguinte modo:

"Art. $8^{\circ}$ Às unidades de enfermagem compete[...]:XIICooperar com os serviços sanitários e agências de saúde, no desenvolvimento de programas que visem a educação sanitária da comunidade. [...]." Cap. I - pag. 23

Iniciativas desse período consideravam o hospital não somente como um ambiente de tratamento de doenças, mas com uma visão mais ampla, tanto é que, em estudo de 1963, Muller ${ }^{(13)}$ conceitua a assistência de enfermagem ambulatorial, no hospital em foco, não exclusivamente atrelada à "prática de curativos, auxílio em exames e procedimentos médicos", mas como um "elo entre o hospital e a saúde pública de campo, e a educação 
sanitária do paciente e seus familiares", pois, por meio dessa prática acreditava que o indivíduo tornar-se-ia "guardião de sua saúde".

Nessa mesma época, desenvolveram-se, no Brasil, outros modelos de inserção de educação sanitária no ambiente hospitalar ${ }^{(14)}$. Como exemplo cita-se o Serviço de Enfermagem Ambulatorial do Hospital das Clínicas de Porto Alegre, com ênfase na educação em saúde, instrução para o autocuidado e atividades individuais e grupais, com envolvimento familiar.

Legislação sobre Saúde, Enfermagem e Trabalho é uma das subcategorias em que se observou-se medidas de regulação laboral, conforme trecho citado a seguir:

"[...] 3-Normas a Seguir: 3.1-Observar que o servidor da C.L.T, marque férias, no mínimo, 15 dias após o vencimento de cada período de 12 meses de vigência do contrato de trabalho (artigo 130 da C.L.T). Em anexo ao modelo de escala segue uma lista com as datas de admissões dos servidores de C.L.T.[...] Cap. III - pag. 104.

Não houve referências, no manual a Mercado de Trabalho e Áreas de Atuação, o que já era esperado, uma vez que ambas se referem exclusivamente ao ambiente externo à instituição, e o manual era destinado a uso interno.

\section{Métodos de intervenção}

A subcategoria Planejamento apareceu em várias oportunidades, com referência exclusiva à atividade do enfermeiro:

Art. $1^{0}$ São atribuições do Diretor:[...] III - Planejar programas de trabalho da Divisão de Enfermagem $e$ acompanhar a execução dos mesmos. [...] Cap. I - pag. 33

A subcategoria Tomada de Decisão apareceu em várias situações, entre elas:

"[...] O enfermeiro-chefe elabora a escala distribuindo as tarefas nas 24 horas, podendo delegar, aos enfermeiros encarregados dos horários da tarde e serviço noturno, a distribuição nos seus períodos de trabalho.[...]" Cap. III pag. 106
Outra atividade inerente ao Serviço de Enfermagem, abordada na subcategoria Supervisão, foi encontrada no seguinte trecho:

Art. $2^{\circ}$. São atribuições do Supervisor:[...] V - Supervisionar os planos de cuidados de enfermagem elaborados pelo enfermeiro-chefe... [...]" Cap. II - pag.34

Nessas circunstâncias, a supervisão era tida como uma atividade desenvolvida por indivíduos no intuito de influenciar positivamente o desempenho das funções dos supervisionados, além do que as funções executadas pelos supervisores eram bem delimitadas, baseadas em ações como, por exemplo, a de substituição imediata das chefias, em caso de ausência das mesmas e planejamento e participação em programas educativos em prol do desenvolvimento dos funcionários da instituição, entre outros. As funções descritas revelam ações estanques, com forte influência da administração clássica e do modelo burocrático, que priorizava a produtividade obtida por meio da ênfase no controle gerencial, rígida hierarquia e racionalização da estrutura administrativa, o que difere da concepção atual de supervisão, vista como um processo dinâmico, que exerce interface entre o paciente, a equipe de enfermagem e o contexto hospitalar, no intuito único de agregar qualidade ao processo de trabalho assistir ${ }^{(15)}$.

Por fim, identificou-se que, mesmo como atividade não propriamente definida como tal, a subcategoria Auditoria estaria exemplificada como se vê no seguinte trecho:

Art. $2^{\circ}$ São atribuições do Supervisor:[...] VI- Avaliar a qualidade do cuidado de enfermagem dispensado aos pacientes; [...] Cap. I - pag. 35.

Embora o exemplo acima não reproduza ação normativa propriamente dita de auditoria na instituição, efetivamente considera-se como uma ação abrangente em termos conceituais, norteada pelo intuito de atingir um padrão de assistência de enfermagem qualificado, fundamentado principalmente na avaliação formal e no controle do serviço de enfermagem, ou seja, uma função de auditoria. 


\section{Prática de administração de recursos humanos}

Na subcategoria Dimensionamento, identifica-se o modo peculiar como era tratada a adequação do pessoal, diante da necessidade de trabalho:

Art. $1^{\circ}$ São atribuições do diretor: [...] V- Elaborar o quadro do pessoal necessário para o funcionamento do serviço. [...] Cap. I- pag. 33

A subcategoria Recrutamento revela os requisitos exigidos para que os profissionais ingressassem, em conformidade com suas devidas funções, a saber:

Art. 18- Os requisitos mínimos para o exercício das funções nas diferentes categorias funcionais, são: Enfermeiro-chefe e obstetriz: a) Diploma de enfermeiro ou de obstetriz $e$ diploma ou certificado de Curso de Administração Hospitalar; b) prática do exercício da profissão, pelo mínimo de um ano[...] Cap.I - pag.27.

Na subcategoria Seleção, são pormenorizadamente definidas as etapas do processo de decisão acerca da adequação do funcionário recrutado para o serviço.

[...] A enfermagem entrevista e opina sobre o candidato previamente selecionado pelo Setor de Seleção[...] Cap.IIIpag. 110

A subcategoria Distribuição enfatizou atitudes gerenciais, conforme as necessidades e situações específicas:

Art. $3^{\circ}$ São atribuições do enfermeiro-chefe: [...] XI -Planejar a distribuição do pessoal visando manter assistência permanente aos pacientes. [...] Cap. I-pag.36

Não haveria de ficar de fora a avaliação das atividades exercidas pelos recursos humanos, através do exemplo da subcategoria Avaliação de Desempenho:

[...] Cabe ao enfermeiro-chefe assessorado pelo supervisor da unidade, preencher os dados da avaliação. [...] Cabe ao diretor da enfermagem a apreciação da avaliação após revisão da assistente e o encaminhamento dos processos. Cap. III-pag. - 111
Por fim, aparece a subcategoria denominada de Educação Permanente, com trecho que fazia referência à capacitação dos recursos humanos:

[...]O servidor recém admitido recebe orientação $e$ treinamento para o preparo técnico ao desempenho de suas atribuições e ajustamento ao serviço[...] Cap. III-pag. 110.

Embora o exemplo acima esteja classificado na subcategoria "educação permanente", os autores do presente estudo, apesar de terem consciência de que a citação acima constitui um exemplo claro do conceito de "educação continuada", decidiram pela classificação nesse item, justificada pelo fato de ser proposta equivalente de educação profissional constante no referencial teórico escolhido. A esse propósito, salientase o contraste entre os conceitos de "Educação Permanente", entendida como uma prática contínua orientada por ações a um público multiprofissional, com metodologia centrada na resolução de problemas objetivando a mudança, e de "Educação Continuada", aplicável no período em que foi escrito o manual, definido como uma prática direcionada a um público uniprofissional, esporádica, baseada na pedagogia da transmissão, que objetiva a apropriação de conhecimento $^{(16)}$.

\section{Prática de administração de recursos materiais}

A subcategoria, denominada Previsão, é apontada em um trecho do manual:

[...] É feito anualmente, em todas as unidades de enfermagem, a previsão mensal de consumo. [...] Cap. I-pag. 117.

A compra de materiais é pouco abordada no manual e, na subcategoria Aquisição, observa-se um processo interno apenas de substituição ou reposição:

Art. $3^{\circ}$ São atribuições do diretor:[...] XVI -Providenciar substituição ou reposição de material e equipamento. [...]Cap. III-pag. 116

Os materiais adquiridos necessitavam de segregação e guarda, logística esta referida na subcategoria Armazenamento, como exemplificado a seguir. 
Art. 10 São atribuições do escriturário da unidade de enfermagem: [...]III- Receber, conferir e guardar o material vindo do Almoxarifado comunicando imediatamente à enfermeira-chefe, qualquer falha. [...] Cap. II- pag.44

A subcategoria conhecida por Conservação mostra a importância do zelo e estabelecimento de condições propícias para a utilização dos materiais:

\section{[...] Compete ao enfermeiro-chefe a verificação do} material e equipamento, providenciando medidas a sua conservação ou substituição. [...] Cap. I- pag. 115

O direcionamento dos materiais para as diferentes unidades do hospital é apresentado em consonância com a subcategoria Distribuição.

[...] O centro-cirúrgico faz a devolução do material esterilizado durante o plantão noturno. Na mesma ocasião, os tambores vazios de gazes são distribuídos. [...] Cap. I-pag. 116.

Os materiais geridos e disponíveis na instituição passavam por revisões de estoque periodicamente, o que é bem definido na subcategoria Controle:

\section{[...] O Controle de material e equipamento, feito} periodicamente em todas as unidades de enfermagem, facilita, ao enfermeiro-chefe, a supervisão, manutenção e substituição dos mesmos. [...] Cap. III pag. 115.

Nesse período, o gerenciamento de recursos materiais, na maioria das instituições hospitalares, constituía uma atividade centralizada em um departamento específico, pautada em padrões e índices máximos e mínimos de estoque, para aquisição, estocagem, controle e distribuição de medicamentos e outros insumos $^{(17)}$; todavia, frente ao exposto, nota-se que a enfermagem desempenhava, ainda que de modo peculiar e autônomo, a gerência desses recursos na instituição, exceto, é claro, nas ações de aquisição, o que denota limitação de ações.

Em direção contrária ao exposto acima, estudos atuais sugerem que os membros da equipe de enfermagem envolvidos no processo de gerenciamento de recursos materiais tem a obrigação de exercer postura ativa frente à tomada de decisões nesse campo, pois, enquanto membro da equipe de saúde, é imprescindível que o enfermeiro decida sobre as condições dos materiais a serem adquiridos, uma vez que os mesmos influenciam diretamente na qualidade da assistência prestada ao cliente $^{(18)}$.

\section{Prática de administração de recursos físicos}

Apenas uma subcategoria desse agrupamento foi referendada no manual - Segurança do Cliente $e$ Profissionais.

Art. $9^{\circ}$ Ao Centro-Cirúrgico (salas de operação) compete: [...]II-Manter em perfeitas condições todo o equipamento das salas de operações, a fim de propiciar um ambiente seguro de trabalho, cooperando com a equipe cirúrgica no que the couber. [...] Cap. I-pag. .23.

Estudos da época apontavam, como primordial, a adoção de medidas de segurança para o paciente nas salas de operações em que a enfermeira, mais do que atentar para a segurança do procedimento em si, deveria possuir uma visão global da gerência de salas cirúrgicas, tomando, por exemplo, iniciativa de elaboração de plano de controle periódico, manutenção de aparelhos e avaliação de riscos de possíveis interações entre gases no ambiente, que poderiam deflagrar explosões ${ }^{(19)}$.

As cinco demais subcategorias não referendadas foram Arquitetura, Projeto, Decoração, Legislação $e$ Denominação de Compartimentos e Riscos Ocupacionais.

Em geral, era discreta a participação da Enfermagem na decisão sobre os projetos relacionados à estrutura física, muito embora se atribuísse importância aos pareceres e colaborações da enfermagem no planejamento das áreas físicas hospitalares, visto que um bom planejamento influenciaria positivamente na produtividade da equipe e na satisfação do cliente. Como exemplo isolado, a literatura científica mostra que decisões importantes, no direcionamento de fluxo e estruturação física do Instituto do Coração do mesmo hospital a que se refere o manual estudado, teve atuante participação de Clarice Della Torre Ferrarini, enquanto esta exercia função de assessora executiva da instituição, fato este mais incomum ainda para a categoria profissional de enfermeira, dada a hegemonia médica nessa instituição(4). 


\section{Prática de administração de recursos financeiros}

Nessa categoria houve referência apenas à subcategoria Orçamento, conforme identifica-se a seguir:

[...] Em janeiro, cada área de supervisão apresenta o seu plano Diretor da T.1, para a sua avaliação - Objetivos especificos: Levantamento de recursos materiais e humanos para elaboração do orçamento programa. [...] Cap. I. pag. 96 e 98.

As subcategorias não expressadas foram Custos, Financiamento e Produtividade.

Muito embora o conteúdo de custos, no ensino de graduação em Enfermagem, só tenha sido sugerido no ano de 2001, através das Diretrizes Curriculares de Graduação em Enfermagem, regulamentadas pela Resolução CNE/CES nº 03 do mesmo ano(20) e, apesar do aumento do número de estudos que aprofundem a análise desta temática como prática de enfermagem terem sido mais evidenciados a partir do início do século $\mathrm{XXI}$, é consenso que as atividades relacionadas à gerência de recursos financeiros, ao longo da história, tenha sido algo inerente à atividade de enfermeiras gerentes.

Talvez a pouca abordagem dada no manual em análise, ao gerenciamento de recursos financeiros refletia os movimentos de rupturas da economia mundial pois, até os anos 1970 quando foi publicado o manual, o Brasil vivia um período de aceleração econômica que teve seu retrocesso a partir da década de 1980 se estendendo até meados de 1990, com o agravamento da crise econômica global que trouxe reflexos negativos à economia brasileira. Isso motivou, a partir de então, a valorização das atividades que racionalizassem os recursos e centralizassem as ações gerenciais no controle dos custos diretos e indiretos envolvidos na prestação de assistência hospitalar (21).

\section{Prática de administração de recursos políticos}

A subcategoria Estrutura Organizacional aparece no manual em várias oportunidades, entre elas:

Art. $7^{\circ}$ - A Subdivisão de Enfermagem é organizada de modo a cobrir áreas especificas de trabalho, constituindo as seguintes unidades de serviço: 1-16 unidades de enfermagem; II-Unidade de Centro Cirúrgico; III-Unidade de Centro Obstétrico; IV- Unidade de Centro de Material de Esterilização; V- Unidades de Serviços de Ambulatório;VI-
Unidade de Serviço de Emergência; VII- Unidade de Creche dos Filhos dos Funcionários; VIII- Unidade de Educação em Serviço; IX-Setor Expediente; X-Turma de Barbearia.[...] Cap.- I pag. 21

Outra subcategoria, Poder e Cultura, aparece exposta da seguinte forma:

[...] Parágrafo $1^{\circ}$ - As funções de enfermeiro-chefe e de "encarregatura" são de confiança do diretor da Subdivisão de Enfermagem. [...] Cap. I- pag. 21

Em sequência, pode-se identificar o conteúdo afim da subcategoria conhecida por Conflito e Negociação:

Art. 20-São atribuições do Supervisor:[...] VIII-Participar de reuniões com o diretor da Subdivisão de Enfermagem analisando problemas relacionados com pessoal, pacientes, equipamentos, material e outros assuntos administrativos. [...] Cap. II-pag. 35.

Na subcategoria Liderança, os atributos do profissional de enfermagem, em específico do enfermeiro, são vistos da seguinte forma:

Art.5 $5^{\circ}$ - São Atribuições do Enfermeiro:[...] V- Liderar uma equipe de enfermagem, quando este método é empregado. [...] Cap. II - pag. 39

A liderança, nesse panorama, já consistia um grande desafio para a Enfermagem, ficando, a cargo da enfermeira, o seu desempenho, uma vez que era ela a autoridade na equipe e quem tomava decisões ${ }^{(22)}$, porém se percebe uma concepção estanque, definindo-a como um método perante uma necessidade, em que o líder leva “ordem para onde há desordem" cujo único objetivo é influenciar pessoas para mera potencializarão de produtividade ou necessidade transitória(23). Conceitos mais atuais que diferem do que se encontra em discussão, qualificam liderança como processo intencional, grupal, inserido na cultura organizacional, no anseio de atingir um objetivo comum(24).

A gestão de pessoas e equipes foi abordada na subcategoria Motivação: 
Art.30-São atribuições do Enfermeiro-Chefe: [...] IXPromover a adaptação e satisfação em serviço do pessoal de enfermagem. [...] Cap. II - pag. 36.

A subcategoria conhecida como Mudança, a seguir é exemplificada:

Art. $2^{\circ}$ São atribuições do supervisor: [...] XVI- Estudar $e$ propor medidas, a fim de melhorar a execução das tarefas de enfermagem. [...] Cap. II - pag. 35.

Por fim, identificou-se a subcategoria Relações Interdepartamentais:

Art. $3^{\circ}$ São atribuições do enfermeiro-chefe: [...] XIXManter relações de trabalho com o corpo clínico e com os diversos departamentos do hospital; Colaborar nos estágios de alunos de enfermagem e outros. [...] Cap. II-pag. 37

\section{Prática de administração de recursos de informação}

A subcategoria nomeada Comunicação apresentou-se da seguinte forma:

Art. 10 - [...] IV-Informar por telefone ao Registro Geral, nome dos pacientes em repouso na clínica; Distribuir correspondências e pacotes aos pacientes. [...] Cap. II - pag. 44.

Aos registros direcionados e específicos para o paciente também correspondem uma subcategoria, nomeada Prontuário do Paciente:

Art. $7^{\circ}$ São atribuições do auxiliar de enfermagem [...] XIII Anotar no prontuário do paciente os cuidados prestados e as observações feitas. [...] Cap. II - pag. 36

A exigência em relação aos registros executados por membros da equipe de enfermagem, datados dessa época, antecipa o protagonismo que os registros tomaram em seguida, pois se acredita que as anotações de enfermagem, além de auxiliarem as decisões acerca da assistência, fornecem dados para investigação, estatísticas e planejamento. Trata-se ainda de um instrumento de suporte legal, quando questionamentos jurídicos ou processuais são feitos acerca de condutas que envolvam a assistência de enfermagem ${ }^{(15)}$.
A subcategoria exemplificada abaixo é chamada de Manuais Organizacionais:

Art. $8^{\circ}$ - Às unidades de enfermagem compete: [...] XIColaborar com Setor de Educação em Serviço, no sentido de manter atualizadas as rotinas de serviço $e$ as rotinas específicas das várias especialidades. [...] Cap. III pag. 107.

Quanto às subcategorias Documentos Administrativos, Impressos e Formulários Eletrônicos decidiram-se por aglutiná-las e exemplificá-las da seguinte maneira, a saber:

[...] Transferência de leito, na mesma unidade: Informar o Registro Geral sobre a transferência, enviando aviso no impresso próprio, assinado pelo enfermeiro-chefe. [...] Cap. II-pag. 64

Paradoxo a essa realidade é que, no ano de 1975, havia planejamento para o desenvolvimento e implantação do Sistema de Informação e Comunicação Hospitalar (SICH) nessa instituição, através de recursos técnicos de processamento eletrônico de dados voltados para a aplicação, em tempo real, que seria composto por três grandes módulos - Sistema de Controle de Pacientes (SCP) , Sistema de Controle Financeiro (SCF) e Sistema de Coleção de Dados (SCD). Fariam parte desse projeto, analistas de sistema da Companhia de Processamento de Dados de São Paulo, médicos, enfermeiros e técnicos de administração hospitalar ${ }^{(25)}$. Este sistema que foi implantado em 1976, passou por sucessivas atualizações e permanece o mesmo até a atualidade (2012).

Após descrição e exemplificação das oito categorias e suas respectivas subcategorias, que definiram a concentração da prática administrativa de enfermagem na instituição em foco, há de se afirmar que essa estrutura contemplou um amplo espectro de abrangência, pois em todas categorias houve citação de ao menos uma atividade administrativa competente aos profissionais de enfermagem. Merecem destaque as cinco das oito categorias que tiveram todas suas subcategorias contempladas, sendo elas - Método de Intervenção, Prática de Administração de Recursos Humanos, Prática de Administração de Recursos Materiais, Pratica de Administração de Recursos Políticos e Prática de Administração de Recursos de Informação. Em contraste com essas, em três das oito categorias houve lacunas, isto é, não tiveram completamente suas subcategorias 
exemplificadas. Foram elas: Bases Ideológicas e Teóricas, Prática de Administração de Recursos Físicos e Prática de Administração de Recursos Financeiros.

Ao passo que se discute a pertinência de contemplação dos componentes da estrutura do conhecimento em enfermagem com o disposto no objeto em análise, observa-se, com os resultados expostos, um paralelo com entraves e dificuldades que a Enfermagem ainda hoje enfrenta, na constante luta em prol da dominação (e legitimação desse domínio) de determinados nichos da administração no ambiente hospitalar. Fala-se isto, pois, enquanto há um legitimo domínio em atividades relativas à gestão de materiais e de pessoal, ocorre um distanciamento do gerenciamento de recursos financeiros e físicos.

\section{CONCLUSÃO}

O manual estudado tinha espectro de abrangência correspondente à complexidade da organização de trabalho da enfermagem na instituição em foco e estava estruturado de forma a permitir o acesso às prescrições sobre o funcionamento da instituição de forma rápida e detalhada. A linguagem adotada, além de ser acessível à equipe de enfermagem, indicava a valorização do modelo

\section{REFERÊNCIAS}

1. Oliveira, MR. Hospital das Clínicas da Faculdade de Medicina da Universidade de São Paulo 1944-1994: histórico, filosofia de trabalho e sua importância no ensino, na pesquisa e na assistência médica. Rev. Hosp. Clin. Fac. Med. São

Paulo. 1994;49(1):1-12.

2. Hospital das Clinicas da Faculdade de Medicina de São Paulo [internet]. História do HC. São Paulo.

[citado 15dec.2011].Disponível em:

http://www.hcnet.usp.br/historiahc/historia2.htm.

3. Borenstein MS, Padilha MICS, Caetano TL, Mancia JR. Hilda Anna Krisch: pioneira na enfermagem catarinense - formação e contribuição. Rev. Bras. Enferm. 2004; 57(3): 366-70.

4. Sanna MC. Clarice Della Torre Ferrarini: o depoimento de uma pioneira da administração em enfermagem no Brasil. Hist. cienc. saúde -Manguinhos. 2003; 10(3): 153-170.

5. Filha RCA, Teixeira EM, Falcão MCO, organizadoras. Manual

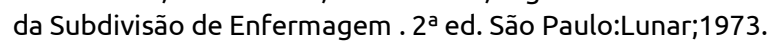

6. Souza JF, Oliveira MMJ. Manual de organização: regimento interno do serviço de Enfermagem: subsídios para sua elaboração. Rev. Min. Enferm. 2002; 6(1/2):91-94.

7. Lucena ICD, Barreira IA, Baptista SS. Cinquentenário do Manual de Técnica de Enfermagem (1957-2007): Contribuições na Construção do Saber de Enfermagem. Esc Anna Nery Rev Enferm 2010; 14 (1): 13-18.

8. Manzo BF, Ribeiro HCTC, Brito MJM, Alves M. A enfermagem no processo de acreditação hospitalar: atuação e implicações no cotidiano de trabalho. Rev. Latino-Am. Enfermagem. 2012; 20(1): 151-158. tradicional-burocrático de organização do Serviço de Enfermagem adotado àquela época.

O fato da análise ter sido feita numa segunda edição da obra demonstra a preocupação com a atualização do texto, por parte de seus autores, a valorização desse instrumento gerencial e a intencionalidade de divulgação desse manual para além dos muros da instituição, o que enfatiza seu papel de modelo-referência.

Nota-se que o conteúdo do manual possuía conformidade com a maior parte das categorias e respectivas subcategorias descritas no referencial teórico escolhido para análise porém, existiu incompletude nos tópicos Recursos físicos e Recursos Financeiros, pois ambos tiveram conformidade com o conteúdo em apenas uma subcategoria. Ressalta-se que o presente trabalho contribuiu para o entendimento de práticas administrativas no âmbito da Enfermagem e que perduram e são reproduzidas até hoje, na instituição de saúde em foco.

Aproveitando o ensejo, sugere-se o estímulo à continuidade na exploração de temas instigantes que permeiam a estruturação histórica de fazer enfermagem nesta instituição ou em instituições similares, seja através de análise de manuais pioneiros como este ou em fontes iconográficas e outros documentos oficiais, entre outros.

9. Polit DF, Beck CT, Hungler BP. Fundamentos de Pesquisa em Enfermagem; Métodos, avaliação e utilização. $5^{\text {a }}$ ed. Porto Alegre:Artmed;2004.

10. Sanna MC. A estrutura do conhecimento em Administração em Enfermagem. Rev. Bras. Enferm. 2007; 60(3): 336-8.

11. Ministério da Saúde (BR). Conselho Nacional de Saúde. Diretrizes e normas regulamentadoras sobre pesquisa envolvendo seres humanos. Resolução 196. 1996. Brasília: CNS; 1996.

12. Formiga JMM, Germano RM. Por dentro da História: O ensino de Administração em Enfermagem. Rev. Bras. Enferm. 2005; 58(2): 222-6.

13. Muller MLG. A Enfermagem-Elemento Chave na Contribuição do Hospital à Saúde Pública. Rev. Paul. Hosp. 1963;11(8):23-25.

14. Heldt E. Serviço de Enfermagem em Saúde Pública do Hospital de Clínicas de Porto Alegre: 40 anos de história [editorial]. Rev. Gaúcha Enferm. 2012; 33(3):10-11.

15. Carvalho JFS, Chaves LP. Supervisão em enfermagem no contexto hospitalar: uma revisão integrativa. Rev. Eletr. Enf. 2009;13(3):546-53[citado 20 ago. 2012] Disponível em: http://www.fen.ufg.br/revista/v13/n3/v13n3a21.htm. 16. Mancia JR, Cabral LC, Koerich MS. Educação Permanente no Contexto da Enfermagem na Saúde. Rev. Bras. Enferm. 2004 ; 57(5):605-10.

17. Fonseca JP, et al. Manual de Organização e Procedimentos Hospitalares. São Paulo: PROASA/FGV/EASP/HCFMUSP. 1978. 18. Honório MT, Albuquerque GL. A Gestão de Materiais em Enfermagem. Ciência, Cuidado e Saúde. 2005; 4(3):259-68. 
19. Castellanos BP. Segurança do paciente em salas de operações: o enfermeiro e a unidade de eletrocirurgia. Rev. Esc. Enf. USP. 1973;7(2):123-39.

20. Francisco IMF, Castilho V. A Inserção do Ensino de Custos na Disciplina Administração Aplicada a Enfermagem. Rev. Esc.

Enferm. USP. 2006;40(1):13-9.

21. Siqueira BT, Schutz V. Enfermagem e o custo com os materiais hospitalares: uma revisão bibliográfica. R. Pesq. Cuid. Fundam. 2010; 2(Ed. Supl.):540-544

22. Secaf V. Liderança: desafios para enfermagem. Enf. Novas Dimens.1977;3(4):250-255.

23. Marquis BL, Huston CJ. Administração e liderança em enfermagem: teoria e prática. Porto Alegre: Artmed; 2005. 24. Amestoy S C. Liderança dialógica nas instituições hospitalares. Rev. Bras. Enferm. 2010;63(5):844-47 25. Pimentel ARA, Ferrarini C, Maschio UV. Processamento de dados no Hospital das Clínicas. Rev. Hosp. Clín. Fac. Med. São Paulo.1975;30(Supl):17-22.

Artigo recebido em 13/06/2012.

Aprovado para publicação em 27/05/2013.

Artigo publicado em 30/09/2013. 